\title{
PET-CT-MRI Applications of Musculoskeletal Disorders, Part I
}

Editors

ALI GHOLAMREZANEZHAD

ALI GUERMAZI

ALI SALAVATI

ABASS ALAVI

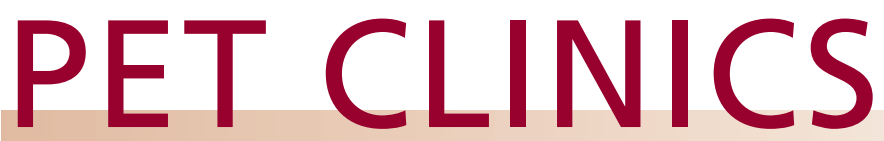

www.pet.theclinics.com

Consulting Editor

ABASS ALAVI

October 2018 • Volume 13 • Number 4 